\title{
USO DA TECNOLOGIA DA INFORMAÇÃO E COMUNICAÇÃOA ESTUDO DE CASO NO CURSO dE CIÊNCIAS CONTABEES
}

\author{
INFORMATION AND COMMUNICATION \\ TECHNOLOGY: A CASE STUDY IN THE \\ COURSE OF ACCOUNTING SCIENCES
}

Paulo Divino Cesar Braga paulocontabil@uol.com.br

Mestre em Ciências Contábeis na Fundação Escola de Comercio Alvares Penteado (São Paulo/Brasil).

Professor na Universidade Estadual de Goiás (Aparecida de Goiânia/Brasil).

Marcos Reinaldo Severino Peters marcos.peter@fecap.br Doutor em Contabilidade e Controladoria pela Universidade de São Paulo (São Paulo/Brasil). Professor na Fundação Escola de Comércio Alvares Penteado (São Paulo/Brasil). 


\section{RESUMO}

As Tecnologias da Informação e da Comunicação (TIC) estão cada vez mais presentes nas atividades profissionais, inclusive do docente. Diante deste aspecto, o presente trabalho foi proposto com 0 objetivo de analisar e identificar a utilização das TIC pelos docentes de um curso de Ciências Contábeis. A pesquisa foi conduzida com professores do Curso de Ciências Contábeis que lecionam em uma instituição de ensino superior localizada em Goiás. Procedeu-se a aplicação de um questionário validado e adaptado aos docentes. Por meio da análise dos resultados, observou-se que o nível de conhecimento sobre informática relatado pelos docentes foi intermediário. Os docentes relataram acesso à internet, especialmente para acessar o e-mail, pesquisar informações e utilizar as redes sociais. Metade do corpo docente incluem softwares da área contábil em suas práticas e citam a necessidade da formação do profissional da contabilidade apto a trabalhar com as tecnologias. Quanto às dificuldades relatadas, incluem a dificuldade em utilizar as tecnologias existentes e a infraestrutura inadequada. Os docentes são proativos frente às TIC e possuem familiaridade com uso da informática, mas concordam que, com maior investimento na infraestrutura da instituição e formação profissional, aumentaria a adoção das tecnologias de forma adequada nas atividades acadêmicas relacionadas à formação do contador.

Palavras-chave: Contabilidade. Ensino superior. Mídias. Professores.

\section{ABSTRACT}

Information and Communication Technologies (ICTs) are increasingly present in professional activities including teaching. In view of this aspect of the present work proposed in order to evaluate the relationship between the professional profile, including teachers titration and age of the Accounting course in a Higher Education Institution and yours practices of education, especially the use of information and communication technologies. The research conducted with Accounting Course teachers, who teach in a state higher education institution located in Aparecida de Goiânia, Goiás. A questionnaire was applied, adapted and validated to teachers. The information on knowledge level reported by teachers was intermediate in of respondents. Everyone has access to the internet and use it to access electronic mail and bibliographical research, followed by the use of social networks. As regards, the reported difficulties include difficulty in using existing technologies and inadequate infrastructure for their use in academic activities. Teachers have positive attitudes towards ICT and familiarity with using computers, but agree that more investment in the infrastructure of the institution and training would increase the adoption of technology appropriately in academic activities.

Keywords: Accounting. Didactic. Higher education. Training. Teachers. 


\section{INTRODUÇÃo}

Perante as mudanças no cenário mundial, o contador necessita de uma constante busca de informações para agregar conhecimentos, tornando-se um profissional competente para exercer seu papel de gestor da informação e utilizar mecanismos para intervir no processo decisório da empresa (GALERA; FERREIRA; GOULART, 2013; SILVA et al., 2017).

Observa-se queas demandas da atualidade têm feito com que os contadores necessitem desenvolver suas habilidades para atender de forma eficiente as exigências do mercado, portanto, capacidades pessoais, domínio do negócio e participação ativa no processo de gestão passaram a integrar o novo perfil do profissional contábil (FAOTTO; JUNG, 2018). Essa evolução ocorreu devido ao crescimento no mercado empresarial, o qual exige profissionais cada vez mais qualificados, especializados e multifuncionais na função a exercer (PELEIAS et al., 2007; SANTOS et al., 2013).

Assim sendo, os Cursos de Ciências Contábeis devem contribuir para a formação de um profissional que integre responsabilidade social e conhecimento técnico-científico, favorecendo a inter-relação com outras áreas da ciência, com a finalidade de proporcionar a aplicação das competências nas mais diversas atividades da profissão (BRASIL, 2004a; BRASIL, 2004b).

Portanto, as Instituições de Ensino Superior (IES), no âmbito da formação do profissional contábil, devem buscar a preparação do egresso para enfrentar tais mudanças; esta busca pelo desenvolvimento e qualidade do ensino, realizada pelas IES, tem figurado como a principal razão para a constante preocupação com a capacitação dos docentes. Segundo Libaneo (2002), é impossível discorrer sobre a qualidade de ensino sem mencionar a formação do docente, questões que estão intimamente relacionadas.

A assertiva supracitada é corroborada às colações de Vasconcelos, Cavalcante e Monte (2012, p. 87), os quais indicam que:

Ao docente é necessário o desenvolvimento de competências que o habilitem a exercer com mais propriedade seu trabalho como educador, incluindo-se domínio da área de conhecimento e didático-pedagógica, comunicação, planejamento, comprometimento e ética, dentre outras. É importante que o docente tenha compreensão da totalidade de seu ofício e desenvolva os atributos percebidos na sua prática docente como essenciais.

Espera-se que as respostas relacionadas ao ensino possam depender de forma significativa das competências dos docentes, pois ao docente cabe uma parcela expressiva da responsabilidade dentro do processo, embora também incida sobre o discente uma parte dessa responsabilidade (LIBANEO, 2002; MARQUES et al., 2018). Ainda, no que se relacionam as competências docentes, Coelho et al. (2014) 
afirmaram que se torna cada vez mais necessário que o docente se aproprie dos recursos tecnológicos, dinamizando o processo de ensino-aprendizagem de acordo com o mundo atual.

Vários são os desafios que se relacionam ao ensino, com a chegada da internet e das diversas mídias educacionais (MORAIS et al., 2014; MORÉS, 2018). Impossivel é negar estas mudanças e ficar alheio a tudo que vem acontecendo. Grande parte dos discentes nasceu nesta era virtual e trazem consigo informações, experiências e muita criatividade aliadas à curiosidade relacionada às TIC (SILVA et al., 2014).

Nos dias atuais, de acordo com Morés (2018), a educação está se fundamentando em uma maior relação entre os cursos presenciais e a distância, utilizando a tecnologia de forma mais expressiva e integrada, sendo que, para que se consiga uma aprendizagem significativa, é necessário que as IES, na figura do docente, em todos os níveis, aprendam como associar o presencial ao virtual, vivenciando uma nova pedagogia da comunicação e gestão.

Oliveira (2013) relata que o ensino sempre esteve ajustado às características de seu tempo e da sociedade na qual as instituições educacionais estavam inseridas. Desta forma, como o cenário atual está pautado na informatização, especificamente nas formas de comunicação e de acesso ao conhecimento, estas novas tendências vêm influenciando o ensino, tanto na formação dos docentes quanto na organização dos currículos e das metodologias de ensino. A popularização das TIC está revolucionando o processo de ensino e aprendizagem, e acredita-se que as mesmas funcionarão como uma ampla rede de construção e troca de conhecimento, mas torna-se necessário identificar se o docente está preparado para tal situação.

Destaca-se que alguns pesquisadores defendem que, para o ensino se concretizar com o bom uso da TIC, é preciso uma mudança de paradigma (SPAGNOLO et al., 2014; SALLUM; CAVALARI JUNIOR; SCHIMIGUEL, 2011; GALDINO et al., 2014; SOUZA-NETO; MENDONÇA, 2017; TORRES; KERBAUY; MICELI, 2018). Os mesmos autores destacaram a necessidade de compreensão, inclusive dos docentes, de que, mesmo com as mudanças ofertadas pelas tecnologias, o docente não perderá sua função no processo de ensino e aprendizagem. O professor será sempre necessário, pois o que muda é o foco e as várias possibilidades de aprendizagem, como a utilização das videoconferências, os softwares educacionais, os chats e sites de pesquisa (COELHO et al., 2014). Deste modo, Paiva e Braga (2009) declararam que, neste novo paradigma, o professor assumirá a função de orientador do conhecimento, um provocador que irá auxiliar no desenvolvimento das habilidades do alunado, deixando de ser apenas o repassador e detentor do conhecimento, se tornando, mais integrado ao processo.

Forest et al. (2014) destacam que a capacitação dos docentes, pelo menos no que concerne à titulação, vem sendo aprimorada. A proporção atual de mestres e doutores em relação ao total de docentes, considerando todas as áreas de conhecimento, atesta tal assertiva. De acordo com dados 
provenientes do Censo da Educação Superior (BRASIL, 2014), dos 362.639 docentes que atuam em cursos de graduação, 10.745 são graduados, 95.589 são especialistas, 141.218 são mestres e 115.087 são doutores.

No que diz respeito ao curso de Ciências Contábeis, o progresso da titulação dos docentes também é mencionado (FOREST et al., 2014). No entanto, Vasconcelos, Cavalcante e Monte (2012) dedicaramse a verificar quais os fatores influenciam no desenvolvimento das competências dos docentes de Contabilidade, tendo utilizado a pesquisa de campo por meio da aplicação de questionários a 267 respondentes. $\mathrm{O}$ autor indicou a necessidade de atenção, principalmente no que se refere a um melhor preparo didático-pedagógico. Ao final, foi sugerido um maior empenho com a qualificação do corpo docente por parte das IES, visando oferecer condições para que as competências necessárias à docência sejam melhor desenvolvidas.

Entretanto, mesmo considerando a significativa qualificação no nível de formação dos docentes de Ciências Contábeis, resta saber se tem ocorrido, simultaneamente a ela, uma evolução nas práticas pedagógicas desses profissionais, que possa fazer frente às exigências e dificuldades de aprendizagem que procedem da complexidade deste cenário atual.

Diante do exposto, o presente trabalho foi proposto com o objetivo de analisar e indicar a utilização das TIC pelos docentes de um curso de Ciências Contábeis de uma Instituição de Ensino Superior, determinando uma possivvel relação entre a utilização destas práticas e a titulação e idade dos docentes. Deste modo, realizou-se um estudo de caso, com abordagem quali-quantitativa, com propósito de buscar uma medida objetiva sobre determinado fenômeno, procurando dar ênfase ao uso de dados sistematizados que possibilitam a elaboração de sínteses, comparações e generalizações.

\section{METODOLOGIA}

A pesquisa foi realizada em Aparecida de Goiânia, município brasileiro do estado de Goiás, localizado na Região Metropolitana de Goiânia. Sua população, conforme estimativas, é de 500.619 habitantes, sendo o segundo município mais populoso do estado, ficando atrás somente da capital, Goiânia. Estendendo-se por uma área de 288,4 km² e ostentando um PIB de R\$ 62.966.990,00 em 2011 (terceiro maior PIB de Goiás atrás de Goiânia e Anápolis), é um dos principais centros industriais do Estado.

Esta pesquisa trata-se de um estudo de caso de caráter quali-quantitativo, realizada com os docentes do curso de graduação de Ciências Contábeis em sua prática de ensino e uso de tecnologia. 0 universo de estudo foi constituído por todos os docentes que ministravam disciplinas no curso de Ciências Contábeis no momento de realização do estudo. 
Os dados da presente investigação foram coletados através de questionário. Quivy e Campenhoudt (2005) destacaram que o questionário é um instrumento de investigação muito utilizado, de modo a facilitar o conhecimento de determinada população e a compreensão de alguns fatores sociais que, de outra forma, seriam difíceis de avaliar. Este instrumento permite o acesso a um número maior de elementos, sistematização da coleta e gestão da informação, permitindo uma metodologia mais rigorosa e um tratamento mais homogêneo dos dados.

O questionário foi formado por um conjunto de perguntas destinadas a gerar dados necessários para atingir os objetivos de um projeto de pesquisa. Segundo Malhorta (2001), o objetivo da aplicação do questionário é obter informações dos entrevistados. O questionário aplicado foi elaborado por meio da adaptação do utilizado pela pesquisadora Lames (2011) e está dividido em cinco blocos:

a. Apresentação e Identificação: o questionário inicia-se com uma breve apresentação dos seus objetivos, bem como dos membros que estão aplicando o questionário;

b. Identificação: em seguida, são solicitadas algumas informações para identificar o perfil do docente, ou seja, os dados demográficos;

c. Estratégias de Ensino: este bloco questiona sobre as estratégias de ensino utilizadas em sala de aula, a intensidade do uso daquela estratégia, bem como os objetivos pedagógicos vinculados ao seu uso (principal e secundário);

d. Tecnologias da Informação e Comunicação: a penúltima parte do questionário procura relacionar a tecnologia utilizada, sua intensidade de uso, com as estratégias de ensino (principal e secundária);

Precedendo a aplicação efetiva do questionário eletrônico, um pré-teste foi realizado com cinco docentes da IES selecionada. O pré-teste torna-se essencial para testar o questionário, ou seja, busca identificar e eliminar problemas potenciais (GIL, 2010). Desta maneira, o pré-teste foi aplicado para um grupo de cinco docentes com áreas de conhecimentos diferentes entre si, bem como níveis de fluência digital diversos. 0 resultado da aplicação do pré-teste foi positivo e resultou na revisão do questionário para atender às dificuldades encontradas pelos docentes e garantir que sua aplicação fosse efetiva.

Após a seleção dos dados, foram seguidas as orientações de Minayo (1992), as quais apontam para a organização dos dados, sua divisão em unidades ou categorias, um esforço de síntese, a procura por padrões e a identificação de aspectos importantes para a compreensão do tema que foi estudado, ou seja, determinação da relação entre o perfil profissional dos docentes do curso de Ciências Contábeis de uma IES e as suas tecnologias de ensino, particularmente, a utilização das TIC. 
Visando descrever e determinar esta relação, foi utilizada a Análise de Estatística Descritiva e o Teste de Comparação de Proporções, entre a variável Formação Acadêmica e Procedimentos Metodológicos de Ensino, nos testes Qui-quadrado de Pearson. Considerou-se o nível de significância de 5\% e utilizou-se o Software R para realização das análises.

\section{RESULtados e ANÁLISE}

Considerando os questionários validados, observou-se que, dos 14 docentes que ministram aulas no curso de Ciências Contábeis, 7 (50\%) são do sexo masculino e $7(50 \%)$ do sexo feminino. Estes dados são similares aos das pesquisas realizadas por Gomes, Gostini e Cunha, (2013). Uma questão que deve ser considerada é o quantitativo de mulheres, assim sendo, os resultados expostos vão de encontro às colocações de Hocayen-da-Silva (2008) que defende que as transformações nos padrões culturais e nos valores relativos ao papel social da mulher foram intensificadas a partir da década de 70, devido aos movimentos feministas. Consequentemente, a presença cada vez mais atuante das mulheres nos espaços públicos alterou a constituição da identidade feminina, cada vez mais voltada para o trabalho produtivo.

Destaca-se que a expansão da escolaridade e o ingresso nas universidades viabilizaram o acesso das mulheres a novas oportunidades de trabalho. Esta situação também é corroborada por Gomes, Gostini e Cunha (2013) que mostraram que os docentes do sexo masculino ocupam 55,7\% das funções docentes, enquanto as mulheres ocupam $44,3 \%$, índices semelhantes aos obtidos no presente estudo. As autoras Gomes, Gostini e Cunha (2013) relataram, ainda, que há uma participação mais efetiva das mulheres na modalidade EaD.

Em contrapartida, em pesquisas realizadas por Lanfin (2005), foram entrevistados 28 docentes de contabilidade, sendo 21 do sexo masculino e 7 (sete) do sexo feminino, correspondendo a $75 \%$ e $25 \%$ do total, respectivamente. Estes dados acentuam, também, a correlação com a pesquisa exposta do CFC, realizada entre 1995 e 1996, com um universo amostral de 300.000 profissionais, entre contadores e técnicos em contabilidade, o qual trouxe um resultado de $72 \%$ do sexo masculino e $28 \%$ do sexo feminino. Por sua vez, Laesker e Cittadin (2010) e Slomski et al. (2014) relataram a predominância de docentes do sexo masculino em cursos de Ciências Contábeis de IES do Estado de São Paulo.

No que concerne à média de idade, cita-se que foi de 36 anos com um desvio padrão de 8,4 anos, 0 que retrata uma amostra heterogênea de docentes quanto à faixa etária. Fato este que, possivelmente, torna-se interessante para o ensino, pesquisa e extensão, em razão da combinação entre a experiência e o vigor dos docentes em início de carreira. 
No que se refere à idade dos docentes, nota-se uma predominância de docentes com idade superior a 40 anos. Este fato é diferente dos relatados pelos pesquisadores Laesker e Cittadin (2010), Lames (2011) e Slomski et al. (2014), os quais realizaram pesquisas em curso de Ciências Contábeis em São Paulo e determinaram maiores frequências para docentes com idade inferior a 40 anos. Considerando os dados da idade e ponderando de acordo com as gerações, relata-se que a maioria dos docentes pertence à geração "X", nascida entre 1965 e 1978. Estes, denominados de imigrantes digitais, são indivíduos, em sua maioria, com faixa etária atualmente superior a 30 anos que, segundo Prensky (2001), nasceram numa época onde a internet não era ainda utilizada em massa como nos dias atuais, em que as tecnologias digitais permeiam o cotidiano da sociedade. Eles imigraram para o universo da cultura digital, interagindo com as ferramentas tecnológicas. No entanto, naturalmente estes não têm intimidade com os recursos de informática num sentido pleno e não expressam muita confiança ao utilizá-los.

Ainda de acordo com Fey (2011), a maioria dos atuais docentes está compreendida nesta categoria de imigrante digital, onde poucos deles têm intimidade com as TIC que deveriam ser utilizadas em seu cotidiano. Conforme o autor, alguns destes professores são contrários ao seu uso na área educativa.

Quanto à formação acadêmica avaliada no presente estudo, notou-se que 7 (50\%) possuem graduação em Ciências Contábeis, 2 (14\%) em Administração, 1 (7\%) em Economia, 1 (7,1\%) em Direito, 1 $(7,1 \%)$ em Matemática, 1 (7,1\%) em Agronomia e 1 (7,1\%) em Pedagogia. Considerando a titulação, obtevese que $1(7,1 \%)$ têm doutorado, $7(50 \%)$ mestrado e $6(43 \%)$ especialização. No que concerne à titulação dos docentes do curso, especificamente os que possuem formação em Ciências Contábeis, identificou-se que todos possuem especialização na área.

Ressalta-se que havia apenas um doutor na IES avaliada no momento da pesquisa (Relata-se que no momento da avaliação haviam quatro docentes finalizando o curso de doutorado), dados bem inferiores aos apresentados por Slomski et al. (2014), os quais determinaram uma frequência de 45\% de docentes do curso de Ciências Contábeis com o título de doutor em IES localizada em São Paulo. 0 fato da baixa frequência de ocorrência de doutores na IES de Aparecida de Goiânia pode se relacionar à não existência de cursos de pós-graduação Stricto Sensu (mestrado e doutorado) na área de Ciências Contábeis, Administração ou Economia no Estado de Goiás (o primeiro curso de mestrado, o curso de Administração, começou a funcionar em Goiás em 2014, na Universidade Federal de Goiás - UFG).

Portanto, a situação supracitada relaciona-se à dificuldade de formação do docente, o qual tem que buscar em outra unidade da federação cursos para a sua capacitação e, muitas vezes, após a conclusão do mestrado, o profissional retorna ao seu Estado para exercer a docência, o que dificulta a saída para o doutoramento. Outro fator que pode dificultar é o enlace matrimonial, pois neste público cita-se que cerca de $90 \%$ são casados ou estão em união estável. 
Ainda considerando estes aspectos, destaca-se que, segundo dados do E-MEC, Goiás atualmente possui 21 IES que oferecem o curso de Ciências Contábeis na Grande Goiânia, incluindo Aparecida de Goiânia, portanto, a criação de outros cursos de Mestrado e Doutorado na área de Ciências Contábeis e áreas correlatas seria viável para a capacitação dos docentes do Estado.

No entanto, apesar da ausência de cursos Stricto Sensu no estado de Goiás, os dados apresentados quanto à titulação demostram que estão de acordo com os publicados pelo CENSO da educação superior em 2013 pelo INEP (BRASIL, 2014), o qual pontua que nos últimos 10 anos o número de mestres e doutores cresceu $90 \%$ e 136\%, respectivamente, pois apesar da baixa frequência de doutores, ocorre uma taxa de mestres significativa na área $(50 \%)$.

Quanto à utilização do computador, para realizar tanto atividades em contexto pessoal como atividades de caráter docente, 100\% (14) declararam fazer uso deste equipamento. Com relação à média brasileira de acesso ao computador, os docentes da amostra se encontram em uma situação melhor, já que, segundo estudo realizado pelo CETIC - Centro de Estudos sobre as Tecnologias da Informação e da Comunicação (CETIC, 2008), apenas $28 \%$ dos domicílios brasileiros possuem computador.

0 acesso à internet pelos docentes da nossa amostra também foi muito superior à média brasileira, de $18 \%$. Ainda de acordo com este estudo realizado pelo CETIC (2008), quanto maior o grau de escolaridade dos indivíduos, maior é o acesso aos equipamentos das TIC. Entre os indivíduos brasileiros com nível superior, por exemplo, o acesso à internet chega a 83\%, apoiando, assim, os resultados encontrados na nossa investigação.

Os dados observados são iguais aos de outros pesquisadores que avaliaram o curso de Ciências Contábeis, assim como Lames (2011) e Slomski et al. (2014), que apontaram que 100\% dos docentes de IES localizadas no Estado de São Paulo possuem e utilizam o computador e a internet em prol das atividades educacionais, dados idênticos ao da presente pesquisa.

Como visto, todos os docentes da IES avaliada possuem computador e utilizam a internet. Quando questionados sobre a utilização da internet e/ou programas no computador, os docentes citaram que utilizam de acordo com os resultados apresentados na Tabela 1. 


\section{CONHECIMENTO

\section{Tabela 1 - Distribuição dos docentes quanto à utilização do computador e principais atividades realizadas no curso de Ciências Contábeis}

\begin{tabular}{llll}
\hline Atividades & Frequência Absoluta & Frequência (\%) \\
\hline Pesquisar informações na web & $14 / 14$ & 100 \\
Enviar e receber e-mail (correio eletrônico) & $14 / 14$ & 100 \\
Chat & $6 / 14$ & 42,85 \\
Jogos educativos & $1 / 14$ & 7 \\
Outros jogos & $6 / 14$ & 42,85 \\
Redes sociais (facebook, twiter, etc) & $9 / 14$ & 64,28 \\
Plataforma moodle da IES & $6 / 14$ & 42,85 \\
Programa de textos & $14 / 14$ & 100 \\
Apresentações (powerpoint) & $14 / 14$ & 100 \\
Programas de desenhos/edição de imagens & $8 / 14$ & 57,1 \\
Folha de cálculos & $14 / 14$ & 100 \\
\hline
\end{tabular}

Fonte: elaborado pelo autor

Observa-se, na Tabela 1, que 100\% dos docentes buscam informações por meio da internet, uma questão que foi apontada especialmente pelos contadores, sendo que seis professores mencionaram que a internet se tornou necessária, quando se observam as questões referentes às leis devido às mudanças constantes. 0 acesso aos sites se torna oportuno para o autoaprendizado do docente e, além disso, todos utilizam para receber e enviar e-mails. Entre os entrevistados, $85,71 \%$ afirmam utilizar a internet com cunho relacionado ao ensino, ou seja, mantém uma comunicação assíncrona com o corpo discente, o que facilita o envio de material e a comunicação. Quanto à utilização do chat, ferramenta considerada síncrona, nenhum dos docentes relataram utilizá-la com fim pedagógico.

Quanto aos programas, ressalta-se que todos apontaram que o advento do power point auxilia a elaboração das aulas, e todos destacaram que observam que os alunos têm uma melhor interação, principalmente quando utilizam alguns recursos do programa, como a imagem (apontado por oito 
docentes). No entanto, 50\% ressaltaram que queriam ter melhor desenvolvimento na utilização do software. Quanto aos editores de texto, $100 \%$ os utilizam para elaborar as avaliações aplicadas. Quanto aos jogos educativos, apenas um docente $(7,1 \%)$ relatou ter conhecimento sobre o tema e $64,85 \%$ apontaram que queriam aprender mais sobre a edição de imagens.

Portanto, de um modo geral, percebe-se que os docentes têm buscado a incorporação das TIC na profissão, contudo, $40 \%$ ressaltam a necessidade de aperfeiçoamento, pois acreditam que a utilização fique subutilizada. Pensando nas ferramentas disponiveis, inclusive neste sentido, seis professores relataram que nunca tiveram capacitação, aprenderam sozinhos e mencionaram, ainda, o quão importante seria um curso na área de formação dos professores que buscasse esclarecer as formas e os meios de utilização dos softwares disponíveis.

Embora possa parecer antagônico, foi relatado por Prensky (2010) que os nativos digitais, ou seja, a maioria dos respondentes do questionário, ao utilizarem as TIC, acabam enriquecendo seu repertório da linguagem escrita e falada. Deste modo, deve-se enfrentar o desafio de compreender e adotar a linguagem que emerge das TIC, de forma a conviver mais harmoniosamente com os nativos digitais, transformando o diálogo e implementando práticas pedagógicas ancoradas nas TIC.

Os dados supracitados são corroborados por outros pesquisadores que apontam que, a partir dos anos 2000, as TIC começaram a ser incorporadas na vida e na atividade profissional de vários educadores e não poderiam ficar para trás quando se considera a contabilidade, já que se observa uma evolução na ciência. 0 contador da atualidade utiliza software diariamente para a realização de suas atividades e mesmo aquelas ligadas à pessoa física tem evoluído, como acaba de ocorrer com imposto de renda (IR), por exemplo, em meados de 2014, quando a receita federal lançou um aplicativo para facilitar o futuro preenchimento da declaração. Portanto, utilizar as TIC torna-se uma competência do contador da atualidade e, felizmente, os docentes da IES têm se mostrado inteirados a esta realidade, conforme dados obtidos. E esta inclusão, Prensky (2010, p. 5) considera como um dos maiores desafios e oportunidades em se ensinar para os nativos digitais, é "descobrir e inventar maneiras de incluir a reflexão e pensamento crítico na aprendizagem, mas fazendo isso na linguagem do nativo digital".

Em relação ao perfil, identificou-se que $80 \%$ dos docentes dedicam cerca de 30 horas semanais à atividade profissional, destes, aproximadamente $13(92,85 \%)$ estão na área de ensino a mais de 5 anos, e 6 deles (42,85\%) exercem a docência como atividade principal.

Quando questionados sobre quais são os recursos em seus computadores de uso pessoal ou da IES, os docentes relataram que possuem e utilizam os seguintes recursos, conforme apresentado na Figura 1. 
Figura 1 - Recursos de informática disponíveis e utilizados pelos docentes de um curso de Ciências Contábeis

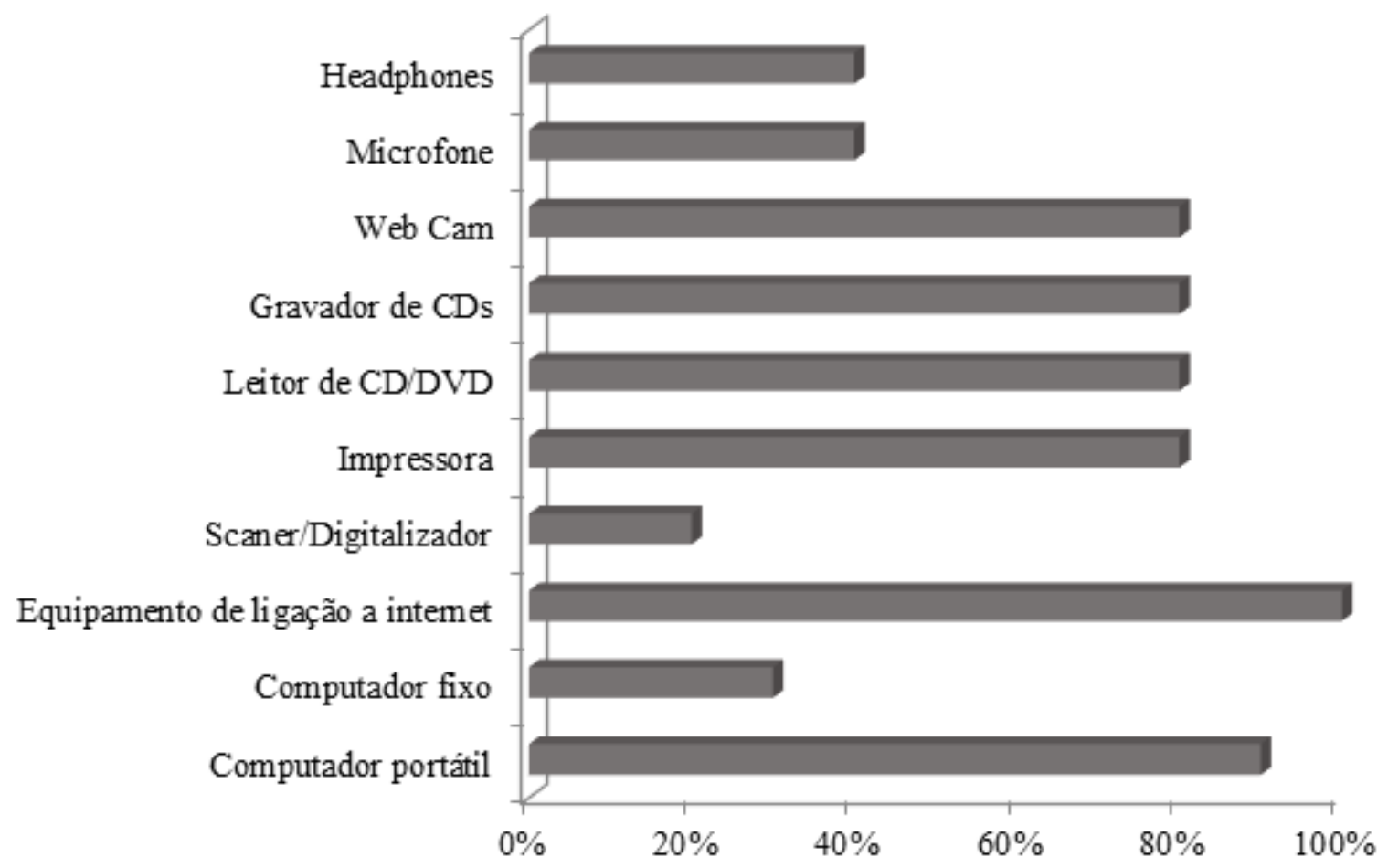

Fonte: elaborado pelo autor

Nota-se que o computador com internet é utilizado por $100 \%$ dos docentes, sendo que mais de $90 \%$ têm computador portátil e aproximadamente $83 \%$ possuem web cam, gravador de $C D$, impressora e leitor de CD/DVD. Relata-se, ainda, que cinco docentes, ou seja, 35,71\%, assinalaram que, apesar de terem os recursos disponiveis em seus computadores, os utilizam com o intuito pessoal e praticamente utilizam apenas a impressora com cunho educacional, ou seja, visando a impressão de material para estudos e avaliações.

Ressalta-se que o docente da atualidade, segundo Forest et al. (2014), para desenvolver seu trabalho, necessita de ferramentas que lhe permitam esta gestão do complexo e a rápida tomada de decisão. Estas ferramentas precisam ser buscadas na observação, na análise, na gestão, na regulação e na avaliação de situações educativas. Porém, para o professor observar, analisar, gerir, regular e avaliar as situações de aprendizagem que ele coloca, necessita de capacitação, fato este apontado pelos docentes da IES avaliada. 
Quanto às questões relacionadas ao nivel de conhecimento sobre a utilização das TIC, itens 20 e 21 do questionário, 57\% dos docentes indicaram ter bom conhecimento e que aprenderam utilizando as ferramentas disponíveis. De um modo geral, ao finalizar esta primeira etapa da pesquisa, os respondentes afirmaram ter ocorrido transformações em seu dia-a-dia devido à inclusão das TIC, em particular os relacionados com a internet, sendo essas modificações relacionadas ao melhor acesso à informação. Dentre outras questões, 92,85\% declararam que ocorreram mudanças na otimização do tempo, 92,85\% responderam que as mudanças influenciaram também em sua comunicação, 78,57\% declararam que houve mudanças em seus relacionamentos para melhor. Assim ficou possível observar, através da presente pesquisa, que as TIC influenciaram e transformaram para melhor a rotina dos respondentes.

No que se refere à plataforma, 92,85\% dos respondentes afirmam que utilizam o Windows e apenas um $(7,14 \%)$ utiliza o Mac OS. Tais dados estão de acordo com o que ocorre em todo o mundo, pois Segundo dados do Market Share, um website que faz pesquisas e estatísticas sobre tecnologia, $88,14 \%$ dos usuários de computador no mundo optam pelo Windows, enquanto apenas 9,77\% utilizam o Mac OS. Os docentes destacaram que na IES o sistema disponível é o Linux e, portanto, o utilizam apenas quando se faz necessário, pois 92,8\% possuem computador portátil, ou seja, notebook. Após este primeiro panorama, serão apresentados os resultados referentes à utilização das TIC pelos docentes, assim sendo, no primeiro momento, visualiza-se na Tabela 2 quais os recursos disponíveis na IES e utilizados pelos docentes.

Kenski (2007, p. 45-46) assinala que as TIC provocaram mudanças na educação, possibilitando mediações entre o docente, o aluno e o conteúdo. Para isso, precisam ser compreendidas e incorporadas pedagogicamente. "Não basta usar a televisão ou o computador, é preciso saber usar de forma pedagogicamente correta a tecnologia escolhida", evidencia a autora. Portanto, acredita-se que a inserção das TIC, deve ser realizada considerando as questões pedagógicas. 


\section{Tabela 2 - Recursos tecnológicos utilizados pelos docentes no curso de Ciências Contábeis}

\begin{tabular}{llll}
\hline Recursos & Frequência Absoluta & Frequência (\%) \\
\hline Quadro de escrever & 14 & 100 \\
Computador & 14 & 100 \\
Projetor de multimídia & 14 & 100 \\
Televisão & 14 & 100 \\
Vídeo & 14 & 100 \\
DVD & 14 & 100 \\
Lousa digital & 0 & 0 \\
Internet (Wireless) & 14 & 100 \\
Jogos educacionais ou simuladores & 1 & 7,1 \\
Laboratório de informática & 12 & 85,71 \\
Softwares da área contábil & 07 & 50 \\
\hline
\end{tabular}

\section{Fonte: elaborado pelo autor}

Através da pesquisa, foi possível constatar que, independentemente da intensidade de uso de cada tecnologia, as TIC apresentadas são utilizadas pelos docentes, exceto a Lousa Digital. Todos apontaram que as utilizam com o intuito de apoiar atividades de ensino e aprendizagem, e estes dados são semelhantes aos apresentados por Lames (2011) e Slomski et al. (2014). As autoras destacam a frequência cada vez mais significativa, principalmente, do computador e projetor multimídia na sala de aula, sendo que Soster avaliou o curso de Administração e Lames e Slomski o curso de Ciências Contábeis.

Em relação à frequência de utilização, $35,71 \%$ dos docentes disseram utilizar os meios em todas as aulas e $50 \%$ em aulas alternadas, conforme a necessidade do tema. Uma docente relatou que na IES avaliada "há apenas quatro projetores (Datashow) e, como são dois cursos, inviabiliza a utilização com maior frequência". O mesmo problema com a disponibilidade de recursos é relatado por mais seis docentes do curso. Apenas um professor tem o equipamento e o leva em todas as aulas. 
O docente $\mathrm{G}$ destacou que é de fundamental importância ter a consciência de que as tecnologias não melhoram o desempenho dos alunos se não vierem acompanhadas de posturas construtivistas, que ajudem os alunos a construírem conhecimento a partir de situações que os façam refletir sobre o mundo que os cercam. Essa premissa é corroborada por Gutierrez (2004, p. 57) quando afirma que "muitos autores veem no desenvolvimento tecnológico mais problemas do que possibilidades de uma vida melhor para o indivíduo. E a aversão a TIC se fundamenta, sobretudo, na crença de que ela é um fim e não um meio".

Um dos docentes relatou que a inserção do computador e projetor multimídia auxilia na inclusão. Apesar da IES estudada não possuir alunos deficientes visuais, auditivos ou mentais, um professor afirmou que a utilização das TIC pode ser inclusiva e servir como elemento enriquecedor de práticas pedagógicas na educação de pessoas com necessidades especiais. Se houvesse disponibilidade de mais computadores e datashows, provavelmente docentes e alunos teriam melhores condições de trabalho.

Na Tabela 3, nota-se um resumo da utilização das TIC na prática docente, independentemente da intensidade de uso.

\section{Tabela 3 - Principais recursos utilizados pelos docentes visando o aprendizado do aluno, no curso de Ciências Contábeis}

(continua)

\begin{tabular}{l|l|l}
\hline Forma de aplicação & Frequência Absoluta & Frequência (\%) \\
\hline Processador de textos & 14 & 100 \\
Apresentações & 14 & 100 \\
Programas de desenhos, edição de imagens & 5 & 35,71 \\
Folha de cálculos & 12 & 85,71 \\
Adobe reader & 14 & 100 \\
Windows movie maker & 5 & 35,71 \\
Windows media player & 9 & 64,28 \\
Multimídia/CD ROOM/ DVD & 14 & 100 \\
Motores de busca na internet & 14 & 100 \\
Enciclopédias livres & 5 & 35,71 \\
\hline
\end{tabular}


(conclusão)

\begin{tabular}{l|l|l}
\hline Forma de aplicação & Frequência Absoluta & Frequência (\%) \\
\hline Dicionários on line da língua portuguesa & 8 & 57,14 \\
Tradutores on line & 8 & 57,14 \\
Sites lúdicos na internet & 2 & 14,28 \\
Vídeos do you tube na internet & 9 & 64,28 \\
E-mail & 9 & 64,28 \\
Softwares específicos da área de contabilidade & 7 & 50 \\
Criação de conteúdos (Wink) & 2 & 14,28 \\
Simulação de jogos & 1 & 7,1 \\
\hline
\end{tabular}

\section{Fonte: elaborado pelo autor}

NaTabela 3, observa-se que 100\% dosdocentes entrevistadosutilizamas TIC, visando, especialmente, organizar e apresentar o material necessário e apoiar as atividades de ensino; 85,71\% utilizam sistema de gestão do aprendizado; $80 \%$ tecnologia da comunicação de um para muitos; 35,71\% tecnologia de busca de informação por meio de enciclopédias livres; 35,71\% ferramentas de manipulação de dados e gráficos; $64,28 \%$ tecnologia de áudio e vídeo; 14,28 \% tecnologia para criação de conteúdo colaborativo; $50 \%$ utilizam softwares específicos da área de contabilidade, o qual se relaciona a área contábil, fiscal e de departamento pessoal; e apenas 7,1\% utiliza a tecnologia de simulação de jogos de empresas. Em torno de $64,28 \%$ dos entrevistados comunicam-se com seus alunos utilizando ferramentas de comunicação de um para muitos, mesmo encontrando semanalmente seus alunos. A atividade de pesquisa é estimulada por aproximadamente $40 \%$ dos docentes, que utilizam as TIC para apoiar esta prática. Um professor relatou que utiliza o software disponivel na IES (Tron Informática - sistema Gerenciador Contábil), e comentou que observa o interesse do alunado e que a prática laboratorial contribui de forma significativa para a formação do aluno.

Outro ponto que deve ser destacado é que nas Ciências Contábeis o uso de tecnologia de simulação de jogos de empresas demanda maior interferência da IES, no sentido de investir na aquisição deste tipo de TIC. Um jogo de simulação pode ser utilizado em qualquer semestre do curso, desde que desenvolvido adequadamente para um propósito específico. Consequentemente, o uso destes tipos de TIC acaba sendo mais restrito e específico, podendo explicar o baixo índice de utilização destes na IES avaliada. 
Quando questionados se os docentes utilizavam os computadores em outras atividades, os resultados obtidos foram os expostos na tabela 4.

Tabela 4 - Forma de utilização do computador para fim didático no curso de Ciências Contábeis

\begin{tabular}{l|l|l}
\hline RECURSOS & Frequência Absoluta & Frequência (\%) \\
\hline Nenhuma & 0 & 0 \\
Produção e edição de informação & 14 & 100 \\
Comunicação e intercâmbio de rede & 14 & 100 \\
Consulta e pesquisa de informação & 14 & 100 \\
Organização e gestão de informação & 7 & 50 \\
Recreativa/jogos & 1 & 7,1 \\
Produção e edição de informação & 7 & 50 \\
\hline
\end{tabular}

\section{Fonte: elaborado pelo autor}

Portanto, conforme apresentado na Tabela 4, observa-se que o docente utiliza as TIC com o intuito de planejar suas aulas, pois a utiliza com a função de produzir, editar e organizar o conhecimento, e tais questões relacionam-se diretamente ao planejamento da atividade docente.

Um ponto que deve ser destacado é que, ao aplicar o teste para determinar se a idade ou a formação influencia na utilização da TIC, não foram encontradas diferenças estatísticas para $p>0,01$, mas relata-se que, se por um lado, espera-se que docentes mais jovens estejam mais familiarizados com o uso das TIC, por pertencerem à geração das novas tecnologias e que, assim, tenham mais facilidade em manuseálas e aplicá-las em contexto educativo, por outro lado, espera-se que docentes com mais idade e maior experiência já tenham construído saberes docentes solidificados, reflexivos e críticos, que possibilitem a conscientização da importância da aplicação das TIC no processo de ensino-aprendizagem.

De acordo com os resultados encontrados, percebe-se que as TIC integradas em sala de aula passam a exercer um papel importante no trabalho dos educadores, se tornando um novo desafio, que pode ou não produzir os resultados esperados. Portanto, assim como colocado por Morais et al. (2014), 
o que transforma a tecnologia em aprendizagem não é a máquina, o programa eletrônico, o software, mas o professor, em especial em sua capacitação e reflexão sobre a inserção das TIC na sala de aula.

Diante da análise dos resultados gerais obtidos, ressalta-se que as TIC não são utilizadas na perspectiva do aluno como autor, e sim para apoiar, em grande parte, a transmissão de conhecimento. Oliveira et al. (2015) relataram que as TIC devem ser inseridas no processo, de modo que proporcionem aos alunos a construção de seus saberes a partir da comunicabilidade e interações com um mundo de pluralidades, no qual não há limitações geográficas ou culturais, e a troca de conhecimentos e experiências é constante. Tal fato transforma-se no desafio da atualidade, pois percebe-se que os docentes estão utilizando as TIC como forma de apoio, fato relatado por vários pesquisadores da educação superior (SPAGNOLO et al., 2014; SALLUM; CAVALARI JUNIOR; SCHIMIGUEL, 2011, GALDINO et al., 2014; TORRES; KERBAUY; MICELI, 2018), e as ferramentas podem ser utilizadas com o intuito de transformar o aluno em protagonista do processo. Portanto, assim como relatado por Souza-Neto e Mendonça (2017), esta transformação trata-se de um processo de aprender e de organizar cognitivamente a informação, pois todos os processos de mudança mental são lentos, levam gerações e não serão visíveis de imediato.

\section{CONSIDERAÇÕES FINAIS}

Diante das questões apresentadas neste trabalho, pode-se dizer que os docentes do curso de Ciências Contábeis da IES avaliada estão utilizando as TIC em suas aulas, porém de forma ainda rudimentar, pois buscam a inserção, mas sem o conhecimento necessário para a aplicação adequada da tecnologia. Notou-se, ainda, que não houve diferença significativa quanto à idade e titulação no que concerne à inserção das TIC no processo de ensino e aprendizagem. Os docentes apontaram que as dificuldades em utilizar as TICS relacionam-se à inexistência de formação em práticas pedagógicas, advindas da formação de base e aperfeiçoamento, na dificuldade da IES em disponibilizar as TIC a serviço da comunidade acadêmica.

Considerando as questões supracitadas, fica claro que cabe ao docente a disposição em repensar, refletir e sugerir caminhos em direção aos avanços tecnológicos, considerando seus objetivos, suas aplicações e as oportunidades que se abrem para uma nova forma de ensinar e aprender, bem como entender e enfrentar as limitações dos profissionais que atuam no ensino superior. 


\section{REFERÊNCIAS}

BRASIL. Ministério da Educação. Conselho Nacional de Educação. Resolução CNE/CES 10/2004. Institui as Diretrizes Curriculares Nacionais para o Curso de Graduação em Ciências Contábeis, bacharelado, e dá outras providências. Brasília: CNE/CES, $2004 a$.

BRASIL. Ministério da Educação. Conselho Nacional de Educação. Resolução CNE/CES 269/2004. Alteração do Parecer CNE/CES n² 289/2003 e da Resolução CNE/CES nº 6/2004, relativa a Diretrizes Curriculares Nacionais do curso de graduação em Ciências Contábeis. Brasília: CNE/CES, 2004b.

BRASIL. Instituto Nacional de Estudos e Pesquisas Educacionais Anísio Teixeira (INEP). Resumo Técnico do Censo da Educação em 2013. 2014. Disponivel em: <download.inep. gov.br/download/superior/ censo/2012/resumo_tecnico_censo_educacao_superior_2012.pdf>. Acesso em: 22 jul. 2017.

COMITÊ GESTOR DA INTERNET NO INTERNET NO BRASIL (CETIC). A evolução da internet no Brasil. 2008. Disponível em: <http://www.cetic.br/media/docs/publicacoes/10/pal2008fisl-04.pdf>. Acesso em: 15 dez. 2017.

COELHO, K. O. et al. Perfil profissional e práticas de docência no curso de Zootecnia. In: Congresso Brasileiro De Zootecnia - Zootec, 22, Vitória, Anais... São Paulo: ABZ, 2014. Disponível em: <http:// www.abz.org.br/anais-zootec-2014.html>. Acesso em: 20 ago. 2017.

FAOTTO, C. L. F.; JUNG, C. F. Perfil e tendências profissionais no âmbito nacional e internacional: um estudo acerca da percepção de acadêmicos de um curso de Ciências Contábeis do Vale do ParanhanaRS. Revista Eletrônica do Curso de Ciências Contábeis, Taquara, v. 7, n. 1, p. 171-199, 2018.

FEY, A. F. A linguagem na interação professor-aluno na era digital: considerações teóricas. Revista Tecnologias na Educação, Viçosa, v. 3, n. 1, p. 57-77, jul. 2011.

FOREST, M. et al. A interdisciplinaridade no curso de ciências contábeis em uma instituição de ensino superior. Revista da Universidade Vale do Rio Verde, Betim, v. 12, n. 1, p. 672-681, 2014.

GALDINO, D. P. N. et al. Avaliação da aprendizagem a partir dos materiais didáticos disponiveis no ambiente virtual de aprendizagem. 2014. Disponível em: <http://esud2014.nute.ufsc.br/anaisesud2014/files/pdf/126821.pdf>. Acesso em: 20 ago. 2017. 
GALERA, K. J.; FERREIRA, G. A.; GOULART, C. P. As principais habilidades, competências e procedimentos técnicos na execução da função nas organizações. Revista Contabilidade \& Amazônia, Sinop, v. 6, n. 1, art. 5, p. 75-91, jan./dez., 2013.

GIL, A. C. Como Elaborar Projetos De Pesquisa. 6. ed. São Paulo: Atlas, 2010.

GOMES, G.; GOSTINI, L.; CUNHA, P. R. Equações estruturais aplicadas ao grau de satisfação dos estudantes do curso de ciências contábeis: estudo em uma faculdade do sudoeste do Paraná. Revista Brasileira de Administração Científica, Aracaju, v. 4, n. 1, p. 18-32, 2013.

GUTIERREZ, S. Mapeando caminhos de autoria e autonomia: a inserção das tecnologias educacionais informatizadas no trabalho de professores que cooperam em comunidades de pesquisadores. 2004. 233 f. Dissertação (Mestrado em Educação) - Universidade Federal do Rio Grande do Sul, Porto Alegre, Rio Grande do Sul, 2004.

HOCAYEN-DA-SILVA, A. J.; ROSSONI, L.; FERREIRA J. R. I. Administração pública e gestão social: a produção científica brasileira entre 2000 e 2005. Revista de Administração Pública, Rio de Janeiro, v. 42, n. 4, p. 655-680, 2008.

KENSKI, V. M. Educação e Tecnologias: o novo ritmo da informação. Campinas, SP: Papirus, 2007.

LAESKER, R.; CITTADIN, A. O perfil dos docentes do curso de ciências contábeis da UNESC e suas estratégias metodológicas. 2010. Periódicos UNESC. Disponivel em: <http://periodicos.unesc.net/index. php/seminariocsa/article/viewFile/1416/1343>. Acesso em: 20 jul. 2017.

LAFIN, M. De Contadora a Docente: a trajetória da docência no ensino superior de contabilidade. Florianópolis: [s.n.], 2005.

LAMES, L. C. J. Docência no ensino superior: o uso das mídias digitais como estratégia pedagógica. 2011. 159 f. Dissertação (Mestrado em Ciências Contábeis) - Fundação Escola de Comércio Álvares Penteado - FECAP, São Paulo, 2011.

LIBÂNEO, J. C. Reflexividade e Formação De Professores: outra oscilação no pensamento pedagógico brasileiro. In: PIMENTA, S. G.; GHEDIN, E (Orgs.). Professor reflexivo no Brasil Professor reflexivo no Brasil: Professor reflexivo no Brasil gênese e crítica de um conceito. São Paulo: Cortez, 2002.

MALHOTRA, N. K. Pesquisa de Marketing: uma orientação aplicada. 3. ed. Porto Alegre: Bookman, 2001. 
MARQUES, M. De L. S. et al. Potencialidades, limites e tensões das diferentes metodologias de aprendizagem. Revista Uningá, Maringá, v. 50, n. 1, 2018.

MINAYO, M. C. S. O Desafio do Conhecimento: pesquisa qualitativa em saúde. São Paulo: Hucitec, 1992.

MORAIS, N. S., et al. Uma revisão de literatura sobre o uso das tecnologias da comunicação no ensino superior. Revista Prisma.com, Porto, n. 24, p. 162-185, 2014.

OLIVEIRA, D. V. Transformando a formação em vocação educacional. 2013. Disponível em: <http:// www.ensinomedio.net/documents/ISBN_978-85-99697-38-2.pdf>. Acesso em: 14 jul. 2017.

OLIVEIRA, C. Tic's na educação: A utilização das tecnologias da informação e comunicação na aprendizagem do aluno. Pedagogia em Ação, v. 7, n. 1, 2015. Disponível em: <http://200.229.32.55/ index.php/pedagogiacao/article/view/11019/8864>. Acesso em: 11 fev. 2018.

PAIVA, V. L. M. O.; BRAGA, J. C. F. Turmas grades e limitações tecnológicas: buscando soluções. Letras \& Letras, Uberlândia, v. 25, n. 2, p. 273-288, jul./dez. 2009.

PELEIAS, I. R. et al. Evolução do ensino da contabilidade no Brasil: uma análise histórica. Revista de Contabilidade e Finanças, São Paulo, v. 1, p. 19-32, Edição 30 anos de doutorado, 2007.

PRENSKY, M. Digital natives, digital immigrants. On the Horizon. MCB University Press, v. 9, n. 5. p. 97$112,2001$.

QUIVY, R.; CAMPENHOUDT, L. V. Manual de Investigação em Ciências Sociais, 4. ed. Lisboa: Gradiva, 2005.

SALLUM, W. G.; CAVALARI JUNIOR, O.; SCHIMIGUEL, J. Concepções de objetos de aprendizagem na matemática: de Jean Piaget a David Wiley. Matemática e Tecnologias. São Paulo: Terracota, 2011.

SANTOS, C. A., et al. A Estilos de aprendizagem: um estudo empírico com alunos do curso de ciências contábeis da Universidade Federal de Mato Grosso do Sul. Revista Razão Contábil \& Finanças, Fortaleza, v. 4, n. 2, jul./dez. 2013.

SILVA, JR. A. T., et al. 2014. Análise da concepção sobre tecnologia de alunos de cursos superiores em informática utilizando mapas mentais. Anais... Proceedings of international conference on engineering and technology education. Disponivel em: <http://proceedings.copec.org.br/index.php/intertech/article/ view/1504>. Acesso em: 10 ago. 2017. 
SILVA, S. E. de S. P. ; COSTA, S. T. F.; SILVA, C. R. A evolução da escrituração contábil à era digital, com foco na escrituração contábil digital e escrituração contábil fiscal: desafios dos contadores no cenário atual. Revista Saber Eletrônico, Jussara, v. 1, n. 3, p. 38, 2017.

SLOMSKI, V. G., et al. New technologies in higher education: possibilities and limits of distance education from the point of view of teachers who work in an accounting class room. 2014. Disponivel em: <http:// www.tecsi.fea.usp. br/envio/contecsi/index.php/contecsi/11contecsi/paper/view/1016>. Acesso em: 22 jul. 2017.

\section{SOSTER, T. S. O. Uso da tecnologia da informação e comunicação no processo de ensino e} aprendizagem: estudo de um curso superior na área de administração. 2011. 134 f. Dissertação (Mestrado em Administração) - Fundação Getúlio Vargas, São Paulo, São Paulo, 2011.

SOUZA-NETO, A.; MENDONÇA L. M.; G. Os Usos das Tecnologias Digitais na Escola: Discussões em torno da fluência digital e segurança docente. Revista e-Curriculum, v. 15, n. 2, 2017. Disponível em: <http://www.redalyc.org/articulo.oa?id=76651641012>. Acesso em: 12 jan. 2018.

SPAGNOLO, C., et al. As tecnologias da informação e da comunicação como mediadoras no processo de formação docente: um recorte nos grupos de trabalho da ANPED de 2009 a 2012. Reflexão e Ação, Santa Cruz do Sul, v. 22, n. 1, p. 203-222, 2014.

TORRES, A. P. ; PIMENTA, KERBAUY, L. A.; MICELI. M. T. O uso efetivo das tecnologias de informação e comunicação (TIC) no ensino superior. Conhecimento \& Diversidade, Niterói, v. 9, n. 18, p. 33-48, 2018. VASCONCELOS, A. F.; CAVALCANTE, P. R. N.; MONTE, P. R. Fatores que influenciam as competências em docentes de Ciências Contábeis. Veredas Revista Eletrônica de Ciências, Caruaru, v. 5, n. 1, p. 86-101, jan./jun. 2012. 